„Przekłady Literatur Słowiańskich”. T. 10, cz. 1

ISSN 2353-9763 (wersja elektroniczna)

DOI https://doi.org/10.31261/PLS.2020.10.01.06

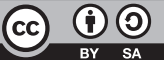

\title{
Na pograniczu twórczości i przekładu: Transfiguration Edwarda D. Blodgetta i Jacques'a Braulta
}

\author{
On the Border Territory between Creative \\ Writing and Translation: Transfiguration \\ by Edward D. Blodgett and Jacques Brault
}

\author{
Joanna Warmuzińska-Rogóż \\ iD https://orcid.org/0000-0001-8195-0099 \\ UNIVERSITY OF SILESIA IN KATOWICE \\ joanna.warmuzinska-rogoz@us.edu.pl
}

Data zgłoszenia: 30.01 .2019 r. ～～Data akceptacji: 1.09 .2019 r.

\begin{abstract}
Transfiguration is a poetry collection in which not only creation is transformed into translation, but it is translation that triggers an act of creative writing. Two Canadian poets, an Anglophone - Edward D. Blodgett and a Francophone - Jacques Brault, conduct an original dialogue: each of them writes a poem in his mother tongue, and then each consecutive fragment is a response to a previous poem, which is an interesting French and English mosaic. Moreover, the volume also gains a strictly translative dimension, as it is Brault who translates Blodgett's poems and vice versa. The unprecedented collection is one of the rare examples of a connection between the two cultures. Furthermore, it is an interesting illustration of the phenomenon of border crossing between cultures, languages and creative activities. The article describes the specificity of bilingual writing and seeks to answer the question about the possibilities of translating a bilingual text into a third language.
\end{abstract}

KEYWORDS | translation, bilingual literature, Canada, Quebec, poetry 
Zdaniem Myriam Suchet, idea, zgodnie z którą przekład może odbywać się jedynie $\mathrm{z}$ jednego języka na drugi, pomiędzy dwoma odrębnymi i stałymi obszarami, to tylko jedna z możliwości. Badaczka wskazuje na japoński krąg kulturowy, gdzie - jak zauważa Naoki Sakai - ważna zawsze była heterogeniczność poszczególnych komponentów: tekstu, języka, tożsamości, i gdzie została ona rozbita poprzez zetknięcie z zachodnim modelem przekładu ${ }^{1}$. Z kolei w Indiach przekład to rodzaj transkreacji opartej na idei reinkarnacji tekstu wyjściowego: przekład postrzegany jest tam jak awatar ${ }^{2}$. Przytoczone przykłady pokazują, że takie nietypowe i bardzo szerokie postrzeganie przekładu, które wychodzi daleko poza tradycyjny podział na oryginał i przekład, to nie jest tylko specyfika Quebecu, choć - warto zaznaczyć - właśnie w Quebecu w obrębie przekładu oraz różnych praktyk okołoprzekładowych dzieje się wiele. Sherry Simon pokazuje, że przekład staje się nosicielem symbolicznej misji, która nie dotyczy już tylko relacji międzynarodowych, lecz także - zwłaszcza w kontekście quebeckim — złożonej tkanki społecznej wewnątrz kraju ${ }^{3}$. Jak pisze badaczka: "Literatura quebecka daje dziś przykłady dzieł, które - traktując o różnicach kulturowych - kładą nacisk na przekład jako proces negocjacji międzyjęzykowej i międzykulturowej”“" Wtóruje jej M. Suchet, stwierdzając, że wiele quebeckich dzieł „gra przekładem, który czasem bywa głównym bohaterem literackim, powodując, że język francuski staje się »dziwnie wyalienowany «" . Możliwości wykorzystania przekładu jest wiele: przekład jako spotkanie kultur pojawia się explicite na poziomie tematycznym (np. tłumaczenie staje się głównym tematem w powieści Le désert mauve Nicole Brossard), ale także bywa sposobem na „wytwarzanie tekstu” (fr. génération textuelle), swoistą poetyką, jak u Abrahama M. Kleina czy interesującego nas Jacques’a Braulta.

1 N. Sakai, 1997: Translation and Subjectivity. Minneapolis, University of Minnesota Press, s. 15.

2 M. Suchet, 2017: Jacques Brault et la nontraduction, un Unland original. „TRANS-”, no. 22, s. 1. Dostępne w Internecie: https://journals.openedition.org/trans/1646 [dostęp: 20.04.2018].

3 S. Simon, 1994: Le trafic des langues. Montréal, Boréal, s. 17.

4 Ibidem, s. 18. Wszystkie przekłady z języka francuskiego i języka angielskiego mojego autorstwa.

5 M. Suchet, 2017: Jacques Brault et la nontraduction..., s. 1. 


\section{O przekładzie bez oryginału}

Jacques Brault jest twórcą wszechstronnym, autorem wielu tomów poetyckich (m.in. Poèmes choisis, L'En dessous l'admirable), sztuk teatralnych, ponadto eseistą, który publikuje zbiory składające się wyłącznie z esejów (np. Chemin faisant), a także zbiory mieszane, w których eseje przeplatają się z wierszami (Poèmes de quatre côtés, Trois fois passera), jest również autorem „kronik” zatytułowanych Ô saisons, ô châteaux ukazujących się w czasopiśmie „Liberté”. Jak podkreśla Michel Lemaire, „Braulta interesuje jego własne odczytanie dzieła, to znaczy jego osobista relacja z tekstem (lektura tekstu jest jednakowo jego przeżyciem i interpretacją). Skupia się on na tych aspektach dzieła, które go poruszyły, i stara się lepiej zrozumieć rolę samego tekstu"6.

Owa osobista relacja $\mathrm{z}$ tekstem widoczna jest w wielu dziełach poety. Co więcej, nieodzownym elementem refleksji Braulta jest także proces tłumaczenia. I tak, w zbiorze Poèmes des quatre côtés (Noroît, 1975) Brault postrzega przekład jako transfer wewnątrzjęzykowy i tym samym znacząco wzbogaca refleksję na temat praktyki przekładowej. Jak pisze S. Simon, „przekład, tak samo zresztą jak poezja, stanowi część projektu wyznaczania obszaru, który może być jedynie wyobrażony"7. Zbiór składa się z czterech części, zawierających w tytułach nazwy poszczególnych kierunków geograficznych, które przeplatają się z czterema fragmentami napisanymi prozą, zatytułowanymi Nontraduire. Całość zamyka końcowa notka od autora, którą można by w zasadzie potraktować jako fotograficzny negatyw, przeciwieństwo wstępu tłumacza. Znajdziemy w niej między innymi odnośniki do wierszy „nieprzetłumaczonych”, jak pisze sam poeta, „pożyczonych” poetów amerykańskich i kanadyjskich: Johna Hainesa (północ), Margaret Atwood (zachód), Gwendolyn MacEwan (wschód) oraz Edwarda E. Cummingsa (południe). „Nietłumacz” (fr. nontraducteur), jak określa siebie Brault, opisuje zapożyczenia i inspiracje, którymi się posłużył. Najciekawszym przejawem owego „nietłumaczenia” jest zapewnienie poety, że przetłumaczył on „wiersze, które nie istnieją w języku oryginału”. Najważniejszym punktem refleksji Braulta na temat przekładu, swoistą kontrteorią, jest refleksja na temat oryginału i jego kopii, jego przekładu':

Ważna jest dla mnie kwestia oryginału. Nie zgadzam się na reprodukcję w przekładzie. Przecież Rembrandt i Goya nie odtwarzali szkiców na kawałku skóry. I jeszcze słynny „model” Platoński, jeszcze piękna Arystotelesowska przyczyna!

6 M. Lemaire, 1987: Jacques Brault essayiste. „Voix et Images”, vol. 12 (2), s. 223.

7 S. Simon, 1994: Le trafic des langues..., s. 59.

8 J. Brault, 1975: Poèmes des quatre côtés. Québec, Éditions du Noroît, s. 84.

9 Por. M. Suchet, 2017: Jacques Brault et la nontraduction..., s. 2. 
Nigdy nie skończymy z uprzedzeniami. Każdy przekład zmienia oryginał, odsyła do niego bezustannie. I stąd „wstyd” przed przekładaniem... chorobliwy strach przed zdradą ${ }^{10}$.

Przekład jest dla Braulta fizycznym doświadczeniem szoku zetknięcia się słów własnych ze słowami cudzymi. Poeta odrzuca wizję przekładu jako imitacji, czyli wersji z gruntu gorszej, drugorzędnej. M. Suchet wskazuje, że w zbiorze quebeckiego twórcy brak wyraźnego rozróżnienia na teksty oryginalne i przełożone, co jest tym bardziej znaczące, że bardzo często w przypadku tłumaczonych wersji mamy do czynienia z edycjami dwujęzycznymi ${ }^{11}$. Wielu krytyków zastanawia się, czy są to wiersze dość luźno zainspirowane wcześniejszymi dziełami, czy też wolny przekład. Sam Brault nie ułatwia zadania, nie podaje bowiem tytułów oryginalnych dzieł, a jedynie tytuły tomów, z których wybrane wiersze pochodzą, podkreślając tym samym, że niecelowa byłaby analiza porównawcza oryginału i przekładu. Co więcej, według S. Simon, usunięcie nazwisk tłumaczonych poetów oraz tytułów ich wierszy to symboliczna dekapitacja ${ }^{12}$. Sam poeta tłumaczy się następująco:

Cytowanie, zwłaszcza w tej sytuacji, stanowi w moich oczach największy przejaw nieprzekładu. Poza wszystkim książka ta składa się wyłącznie z cytatów, fałszywych lub prawdziwych, wskazanych lub nie. Jak powiedziałby Wou Tsien Ki, „[j] eśli ktoś porywa słowa z twoich ust, nie krzycz, że cię okradają, język do nikogo nie należy - w przeciwieństwie do ciszy"13.

\section{Zdaniem M. Lemaire’a:}

Przekład jest zdradą, wiemy to, a poezja jest nieprzekładalna. Brault akceptuje te założenia i będzie mówił o „nieprzekładzie”, żeby pokazać, że jego zdaniem mniej chodzi o niemożliwą wierność niż o wierność wobec ukrytego znaczenia, wobec podstawowego rytmu, wobec głosu. Jest to „nieprzekład”, bo zamiast próbować przenosić sens z jednego języka do drugiego, będzie on pracował nad

10 J. Brault, 1975: Poèmes des quatre côtés..., s. 33.

11 M. Suchet, 2017: Jacques Brault et la nontraduction..., s. 2.

12 S. Simon, 1994: Le trafic des langues..., s. 67. Irène Sotiropoulou-Papaleonidas dokonała analizy zarówno zbioru Poèmes de quatre côtés Braulta, jak i przełożonych na język angielski przez Barry’ego Callaghana wierszy ze zbioru Moments fragiles autorstwa Braulta i doszła do wniosku, że przekład Callaghana jest dużo bardziej swobodny niż ten, którego dokonał Brault, $\mathrm{z}$ tą wszak różnicą, że Callaghan umieszcza wiersze w oryginale i w przekładzie, w formie klasycznego wydania dwujęzycznego, natomiast Brault nie umieszcza nawet dokładnego odnośnika do oryginału. Por. ibidem, s. 67.

13 J. Brault, 1975: Poèmes des quatre côtés..., s. 95. 
wymyśleniem go na nowo w drugim języku, a zatem nad stworzeniem drugiego tekstu, obcego względem obu autorów ${ }^{14}$.

Annie Brisset widzi w pomyśle Braulta cechy charakterystyczne dla przekładów w literaturach rozwijających się (fr. en émergence), w których nazwiska autora i tłumacza mieszają się, co nie tylko skutkuje swobodą w tłumaczeniu, lecz także w wielu przypadkach stanowi projekt ideologiczny. Inną ważną cechą tych literatur, a do takich należy z pewnością literatura quebecka, jest „nadświadomość językowa” (fr. surconscience linguistique), która polega na tym, że „proponuje się w ramach problematyki tożsamościowej refleksję nad językiem oraz sposobem, w jaki wyrażają się relacje języki/literatura w różnych kontekstach"15.

\section{Transfiguration: płynne przejście między oryginałem a przekładem}

W Poèmes de quatre côtés mamy do czynienia z grą między „ja” a innym, drugim, natomiast w Transfiguration — opublikowanym w roku 1998 jednocześnie w wydawnictwie Noroît i BuschekBoobs ${ }^{16}$ zbiorze poetyckim, w którym twórczość nie tylko płynnie przekształca się w przekład, ale także przekład staje się punktem wyjścia dla aktu twórczego - chodzi raczej o dialog pomiędzy dwoma „ja”, a zatem o relację między „ja”, które płynnie przechodzi w „ty”17. Transfiguration to drugi zbiór poetycki napisany w dwugłosie. Po raz pierwszy Brault pracował w ten sposób z Robertem Melançonem, czego owocem był tom Au petit matin (1993).

Jak stwierdzają Michel Biron, François Dumont i Élisabeth Nardout-Lafarge, „W świetle doświadczenia "nieprzekładu«, [...] otwiera się perspektywa »sensu

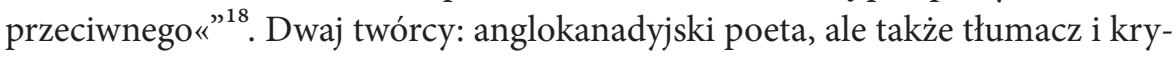
tyk literacki Edward Dickinson Blodgett oraz francuskojęzyczny autor Jacques

14 M. Lemaire, 1987: Jacques Brault essayiste..., s. 232.

15 L. Gauvin, 2000: Langagement. Lécrivain et la langue au Québec. Montréal, Boréal, s. 8.

16 Warto dodać, że quebeckie wydawnictwo Noroît specjalizuje się wyłącznie w publikowaniu poezji, natomiast wydawnictwo BuschekBooks z Ottawy, poza poezją, którą chętnie wydaje, słynie także z przekładów, często publikowanych w wydaniach dwujęzycznych.

17 M. Suchet, 2017: Jacques Brault et la nontraduction..., s. 2.

18 M. Biron, F. Dumont, E. Nardout-Lafarge, 2007: Histoire de la littérature québécoise. Montréal, Boréal, s. 404. 
Brault, prowadzą niezwykły dialog opisany i wyjaśniony w dwugłosie wstępnym: Prefatory Note Blodgetta oraz Liminaire Braulta. Zbiór „wierszy prowadzących dialog czy też wierszy na dwa głosy” inspirowany był japońską rengą, gatunkiem poetyckim opierającym się na twórczym współudziale wielu poetów, którzy komponują wiersz zgodnie ze ściśle określonymi regułami. W japońskiej rendze zasady dotyczące tematyki oraz budowy wiersza, a także wytyczne leksykalne zostały najpierw ściśle określone w epoce Kamakury (1185-1333) i Muromachi (1333-1336), a uproszczeniu uległy dopiero w epoce Edo (1600-1868), kiedy to dla przykładu pozwolono na użycie słów pochodzenia chińskiego, wcześniej zabronionych. Ważny jest układ sekwencji: pierwsza zwrotka rengi, hokku, musi obligatoryjnie zawierać nazwę pory roku. Co ważne, pory roku nie mogą pojawiać się w kolejności wstecznej. Dane słowo nie powinno zostać użyte dwukrotnie. Odniesienie do wiosny lub jesieni ma zawierać się w trzech do pięciu wersów, natomiast opis lata lub zimy w jednym do trzech wersów itd. ${ }^{19}$

Kanadyjscy poeci inspirują się rengą, w żadnym jednak razie nie przestrzegają jej zasad. Ograniczają się do skopiowania pomysłu wiersza skomponowanego przez więcej niż jednego autora, nie narzucają sobie natomiast żadnych ograniczeń formalnych poza z góry przyjętą zasadą tworzenia w swoich językach ojczystych. Brault podkreśla we wstępie: „Nie wiedzieliśmy, dokąd dojdziemy, nie mieliśmy także żadnych wcześniej ustalonych zasad. Każdy z nas pisał w swoim języku i we własnym stylu, odpowiadając jednak drugiemu pośrednio. Następnie dość swobodnie tłumaczyliśmy się wzajemnie”20.

Zazwyczaj w dwujęzycznych zbiorach poetyckich obie wersje językowe znajdują się na sąsiadujących stronach. Danielle Risterucci-Roudnicky słusznie podkreśla, że „dwujęzyczność poetyckiego wydawnictwa pociąga za sobą materializację związku między oryginalnym wierszem a jego tłumaczoną kopią"21. Układ wierszy może być różny, zależy od sposobu rozmieszczenia w przestrzeni (układ horyzontalny, wertykalny, po przekątnej), od zajętej przestrzeni (bardziej skoncentrowany bądź ekspansywny), od kierunku lektury (od oryginału do przekładu i odwrotnie), miejsca umieszczenia nazwiska autora i tłumacza, wzmianki o tytule wiersza ${ }^{22}$. W przypadku Transfiguration jest inaczej: w zbiorku, podobnie zresztą jak w tomie Poèmes de quatre côtés, ważne są miejsca puste, które współgrają z brakiem symetrii, burzącym tradycyjny podział na dwie wersje językowe. Przy czym warto mieć w pamięci, że nawet gdy mamy

19 M. Suchet, 2017: Jacques Brault et la nontraduction..., s. 3.

20 E.D. Blodgett, J. Brault, 1998: Transfiguration. Saint-Hippolyte (Québec), Noroît et Toronto, BuschekBooks, s. 9.

21 D. Risterucci-Roudnicky, 2008: Introduction à l'analyse des ceuvres traduites. Paris, Armand Colin, s. 125.

22 Ibidem. 
do czynienia ze zbiorem poetyckim dwujęzycznym, gdzie oryginał i przekład umieszczone są symetrycznie na sąsiadujących stronach, to w istocie wrażenie symetrii języków jest złudne. Pisze o tym D. Risterucci-Roudnicky, konstatując, iż „bezpodstawność dyptyku, przeżytego w cierpieniu, wzmaga rozdarcie języków, bolesne doświadczenie"23. Z kolei Mouloud Mammeri, autor dwujęzycznej antologii poezji kabilskiej w przekładzie na język berberyjski i francuski, zauważa: „Różnice, czy też raczej różnica nie uwidacznia się w formie wiersza: odpowiedniki są w zasadzie zachowane. Różnica ukrywa się w sensie i wartości, jakie są właściwe dla dwóch całości, tak bardzo, że mamy do czynienia z dziwnym rezultatem w obu tekstach, w których szczegóły do siebie przystają, a ogólne wrażenie się różni”24.

Gdy weźmiemy do ręki tomik Blodgetta i Braulta, zauważymy niezwykły układ tekstów w obu językach. M. Suchet mówi o relacji nie przekładowej, lecz dialogicznej, wersje nie stanowią bowiem powielenia treści, lecz wzajemnie sobie odpowiadają ${ }^{25}$. Z kolei według słów M. Birona, F. Dumonta i É. Nardout-Lafarge, „przyjęcie wielu głosów, które definiują tożsamość jako spotkanie, jest także przyjęciem sprzeczności”26. Przekład znajduje się zawsze poniżej oryginału, następnie - na kolejnej stronie - ów przekład inicjuje fragment oryginalny w języku przekładu. I ponownie u dołu kolejnej strony pojawia się tłumaczenie w drugim języku itd. Spójrzmy na początek zbioru:

[strona parzysta, s. 10]

bees were dancing in the roses

translucent in the light

the petals of a thousand suns

opened in the air

petals of suns dancing in the circles

of music and bees

les abeilles dansaient parmi les roses

translucides sous la lumière

les pétales de mille soleils

se dépliaient dans l'air

pétales de soleis qui dansaient en cercles

de musique et d'abeilles

23 Ibidem, s. 126.

24 M. Mammeri, 2001: Poèmes kabyles anciens. Paris, La découverte, s. 7.

25 M. Suchet, 2017: Jacques Brault et la nontraduction..., s. 5.

26 M. Biron, F. Dumont, E. Nardout-Lafarge, 2007: Histoire de la littérature québécoise..., s. 404. 

[strona nieparzysta, s. 11]
au vent d'été les soleils
traqués d'ouest en est
confient leur semence
les jardins sous la sécheresse
brûlent avec l'alouette
perchée sur son extase

under the summer wind suns

harried from west to east

bestow their seed

gardens in drought

burn as the lark burns

high upon its ecstasy
[strona parzysta, s. 12]
bright seminarian devotee
of summer and the sun the lark
ascending rises in the air
beyond the reach of joy
voice suspended
in the pitch
of solitude

ardente séminariste fervente

de lété comme du soleil l'alouette

sélance et monte dans les airs

hors d'atteinte de la joie

voix suspendue

dans la tonalité

des solitudes ${ }^{27}$.

Każdy poeta pisze wiersz w swoim języku ojczystym, a kolejny utwór to kontynuacja przekładu i odpowiedź na wiersz poprzedni, co stanowi intrygującą francusko-angielską przeplatankę. Ważny jest także rozkład tekstu na stronie: a zatem w zaprezentowanym przykładzie na stronie parzystej (s. 10) tekst angielski, oryginalny, wyjustowany jest do lewej strony. Następujący po nim przekład francuski, na tej samej stronie, wyjustowany jest do środka. Na

27 E.D. Blodgett, J. Brault, 1998: Transfiguration ..., s. 10-12. 
kolejnej, sąsiedniej stronie, quebecki poeta pisze swój fragment inspirowany wcześniejszym przekładem: jego tekst jest także wyjustowany do środka. Poniżej następuje tłumaczenie na język angielski, wyjustowane do lewej strony. I wreszcie gdy odwrócimy stronicę, zobaczymy kontynuację po angielsku, tym razem wyjustowaną do środka. Po niej następuje francuski przekład, wyjustowany do lewej strony, itd. Jak zauważa Catherine Leclerc, na dwujęzycznych stronach każdy wiersz „oryginalny” jest jednocześnie tekstem źródłowym (generuje powstanie następnego wiersza) oraz tekstem docelowym (odpowiedzią na wiersz poprzedni). Owym tekstom wyjściowym odpowiadają na dole każdej strony bardziej konwencjonalne przekłady. Ważne jest także to, że zmienia się na następnej stronie kolejność pojawienia się danych języków ${ }^{28}$. Każde dwie sąsiadujące strony $\mathrm{z}$ czterema tekstami można zatem czytać $\mathrm{w}$ różnym porządku: możliwych jest wiele permutacji ${ }^{29}$.

Ten ze wszech miar oryginalny zbiór stanowi jeden z rzadkich przejawów połączenia obu literatur: quebeckiej i kanadyjskiej oraz ciekawą ilustrację zjawiska pogranicza kultur, języków i działań (od)twórczych. Sam Blodgett, odnosząc się do poetyki rengi, pisze o tanecznym pas de deux:

Jeden tancerz musi poddać się drugiemu, żeby stworzyć figurę, której wymaga sam taniec, nie tancerze. Zdecydowaliśmy się nazwać tę rengę „transfirugacja”, żeby pokazać, w jaki sposób każdy tancerz, pozostając sobą, przyjmuje figurę właściwą dla obu tancerzy, którzy stają się jednym, niewymyślonym przez żadnego z nich. Jedynie wiersz, w którym biorą udział, jest w stanie sobie to wyobrazici ${ }^{30}$.

Wtóruje mu Brault w swoim wstępie: „Jeśli poezja jest także głosem jednego w drugim, to ta książeczka stanowi być może, pod wieloma względami, transfigurację" ${ }^{31}$. Co ważne, $w$ tak skonstruowanym zbiorze zaciera się to, co własne i cudze, a zatem przetłumaczone, i - na dodatek - to, co cudze, staje się punktem wyjścia do twórczości własnej. S. Simon przekonuje, że

[j]est to wzajemne pisanie podniesione na najwyższy poziom, w którym słowa nigdy nie przynależą do jednego głosu. W miarę jak dialog posuwa się naprzód, tworzy się współzależność między głosami poetów. Transfiguracja ukazuje pragnienie eksploracji potencjału przekładowego, żeby rozerwać własność i po-

28 C. Leclerc, 2014: Bilinguisme officiel et traduction au Canada: les interprétations littéraires de Patrice Desbiens et de Jacques Brault / E. D. Blodgett. „Meta”, vol. 59 (3), s. 497.

29 Ch. Melançon, 2000: Traduire la poésie. Présentation. „Ellipse”, no. 64, s. 12.

30 E.D. Blodgett, J. Brault, 1998: Transfiguration..., s. 8.

31 Ibidem, s. 9. 
siadanie. Obie wersje, zamiast podtrzymywać rozdział między językami i tożsamościami, mieszają je. Głos każdego z poetów przenikają akcenty, słownictwo oraz wrażliwość drugiego poety ${ }^{32}$.

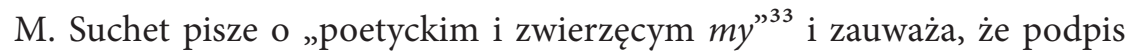
pojawia się w tym wypadku nie explicite, ale ukryty jest w samym tekście ${ }^{34}$. C. Leclerc dostrzega w dwugłosie Braulta i Blodgetta „odpowiedniość połączoną z oddaleniem" ${ }^{35}$ : jest zatem podobieństwo, które jednak ustępuje miejsca różnicy, wynikającej między innymi z innej ortografii, mimo podobnego brzmienia (np. onomatopeja odsyłająca do odgłosu, jaki wydaje ptak - po francusku „fi-bi”, po angielsku „phee-bee”) ${ }^{36}$.

\section{Przekład jako akt polityczny}

Pomysł Braulta i Blodgetta, ze wszech miar oryginalny, nie jest tylko poetycką zabawą, skądinąd niezwykle ciekawą. S. Simon zauważa:

Trudność, o której wspomina Jacques Brault w relacjach z językami, nie jest poetycka. Jest ona głęboko zakorzeniona w kontekście historyczno-politycznym Quebecu. Jacques Brault od zawsze jest uważnym krytykiem rozwiązań siłowych, które rozgrywają się na pisarskiej scenie. Jak wychwalać przekład w kontekście „nadświadomości” językowej w Quebecu? ${ }^{37}$

W swoim eseju Brault pisze, że Quebekczycy nie lubią „ani tłumaczyć, ani być tłumaczonymi”, jako że „klucze do przekładu należą do tych, którzy mają władzę”, stwierdza też, że mimo iż nie ma uniwersalnego języka, to są języki, które kolonizują, czego mieszkańcy Quebecu doświadczają na co dzień ${ }^{38}$. Stąd pomysł Braulta na „nontraduction” w przypadku Poèmes de quatre côtés, czy też na „inter-texte”, który nie jest „ani mój, ani innego”39, w przypadku Transfiguration. Będąc zatem przeciwnikiem literatury narodowej („sam koncept literatury

32 S. Simon, 2006: Translating Montreal: Episodes in the Life of a Divided City. Montréal \& Kingston, McGill-Queen's University Press, s. 140-141.

33 M. Suchet, 2017: Jacques Brault et la nontraduction..., s. 6.

34 O podpisie autora jako hieroglifie wpisanym w sam korpus tekstu pisał Brault w eseju Le double de la signature.

35 C. Leclerc, 2014: Bilinguisme officiel et traduction..., s. 500.

36 E.D. Blodgett, J. Brault, 1998: Transfiguration..., s. 41.

37 S. Simon, 1994: Le trafic des langues..., s. 63.

38 J. Brault, 1975: Poèmes des quatre côtés..., s. 16.

39 Ibidem, s. 50. 
narodowej jest antyliteracki”40 $)$, Brault tworzy koncepcje, które wywodzą się wprost ze specyficznej sytuacji społeczno-politycznej Quebecu oraz z dominacji języka angielskiego nad językiem quebeckim.

Ów poetycki dwugłos łączy się zatem w przypadku Braulta nierozerwalnie z jego doświadczeniem quebeckości. Z kolei dla Blodgetta ważny wydaje się sam proces tworzenia, który współgra zawsze ze specyficznym, jednostkowym odczytaniem tekstu, skąd niedaleko już do samego przekładu. „Istnienie i przetrwanie przekładu ma za zadanie doprowadzić nieuchronnie czytelnika do kwestii, jak aktualizuje się znaczenie, ukazując w końcu, że w każdym nowym odczytaniu nawet tekst wyjściowy nie jest stały, lecz stanowi część tego samego procesu” - przekonuje Blodgett ${ }^{41}$. Jednocześnie nie kryje on, że oficjalna idealna kanadyjska dwujęzyczność jest fikcją: „binarność w Kanadzie, choć sprawia wrażenie pełnego agresji zastoju, tak naprawdę jest anglofońską hegemonią"42.

Zdaniem C. Leclerc, przekształcenie tradycyjnej formy dwujęzycznego tomu poetyckiego stanowi krytyczną interpretację kanadyjskiej polityki językowej opartej na odgórnie zarządzonej dwujęzyczności i konieczności tłumaczenia wszystkiego na oba języki, angielski i francuski ${ }^{43}$. S. Simon idzie jeszcze dalej: „Choć tom Transfiguration unika eksplicytnych odniesień politycznych, to może być prawdopodobnie odczytany jak parodia symetrycznej dwujęzyczności”44.

\section{Gdy oryginał i przekład stanowią jedno}

W przypadku „klasycznych” dwujęzycznych antologii poetyckich można się zastanawiać, czy mamy do czynienia z przekładami, skoro - jak pisze D. Risterucci-Roudnicky - „poezja znajduje się w centrum najbardziej zażartych polemik dotyczących »nieprzekładalności«, zwłaszcza jeśli antologiści są tłumaczami,

40 J. Brault, 1982: Mûrir et mourir. W: La Poussière du chemin. Montréal, Boréal, s. 31.

41 E. Blodgett, 1991: Towards a Model of Literary. Translation in Canada. „TTR: traduction, terminologie, rédaction”, vol. 4 (2), s. 203. W 2012 roku E.D. Blodgett wydał tomik zatytułowany Phrases (Noroît), w którym zdecydował się na tworzenie w dwóch językach, angielskim i francuskim, powielając schemat znany z Transfiguration. Pisze zatem najpierw po francusku, a następnie umieszcza wiersz w języku angielskim, który jest, a zarazem nie jest przekładem.

42 E.D. Blodgett, 1982: Configuration. Essays in the Canadian Literatures. Downsview, ECW Press, s. 9.

43 C. Leclerc, 2014: Bilinguisme officiel et traduction..., s. 497.

44 S. Simon, 2006: Translating Montreal: Episodes in the Life of a Divided City. Montréal \& Kingston, McGill-Queen's University Press, s. 140. 
poetami lub poetami-tłumaczami”45. $\mathrm{Z}$ drugiej jednak strony, co podkreśla sama badaczka, „podwójna, nieprzystawalna, a przecież niezbędna, dwujęzyczna antologia ze swej natury jest poetyką przekładu wcieloną w życie" ${ }^{36}$. W przypadku Transfiguration sprawa jest o tyle ciekawa, że nie ma mowy explicite o tomie dwujęzycznym: przekład stanowi tutaj przede wszystkim sposób na génération textuelle - wytworzenie tekstu. Można powiedzieć o nim, posiłkując się słowami Edwarda Balcerzana, że jest to „wielojęzyczn[y] kalejdosko[p], stanowiąc[y] konsekwentną regułę poetyki pojedynczego dzieła", o którym zresztą mówi badacz, że występuje niezwykle rzadko ${ }^{47}$.

Spróbujmy przedstawić tomik Braulta i Blodgetta za pomocą schematu:

ORYGINAE

oryginał angielski $\rightarrow$ przekład francuski $\rightarrow$ oryginał francuski $\rightarrow$ przekład angielski itd.

Gdyby wyobrazić sobie hipotetycznie przekład dzieła Blodgetta i Braulta na język trzeci, na przykład język polski, należałoby przyjąć któryś z języków za oryginał, a drugi za przekład. Przypomnijmy, że swoistym usankcjonowaniem przekładu obecnego wewnątrz dzieła jest fakt, że tom został uhonorowany Prix du Gouverneur général w kategorii „Przekład” (1999), przy czym nagrodę otrzymał tylko Brault jako tłumacz z języka angielskiego na język francuski, w którego pracy przekładowej doceniono wirtuozerię oraz precyzję. Tym samym niejako od razu wskazano, że oryginałem jest tekst angielski ${ }^{48}$ :

$$
\begin{aligned}
\text { oryginał angielski } \rightarrow & \text { przekład francuski } \rightarrow \text { oryginał francuski } \rightarrow \\
& \text { przekład angielski itd. }
\end{aligned}
$$

\section{PRZEKŁAD NA JĘZYK POLSKI}

oryginał angielski w polskim przekładzie $\rightarrow$ przekład francuski $\rightarrow$ oryginał francuski $\rightarrow$ przekład angielski w polskim przekładzie itd.

Byłoby to, rzecz jasna, całkowite sprzeniewierzenie się idei utworu, który jest inherentnie dwujęzyczny. Co więcej, wybierając jeden z języków, dokonujemy tego, z czym walczy Brault, który poprzez swoją twórczość pokazuje, że pisanie w danym języku jest zawsze aktem politycznym. Sens Transfiguration to nieodzowne połączenie tego, o czym piszą obaj poeci, wzajemnie przekazujący sobie pałeczkę, ale także tego właśnie, jak piszą, czyli przeplatają wzajemnie

45 D. Risterucci-Roudnicky, 2008: Introduction à l’analyse..., s. 127.

46 Ibidem, s. 129.

47 E. Balcerzan, 2011: Tłumaczenie jako „wojna światów”. Poznań, Wydawnictwo Naukowe UAM, s. 100.

48 Por. C. Leclerc, 2014: Bilinguisme officiel et traduction..., s. 497. 
swoje słowa, „transfigurują", by odnieść się do tytułu zbioru, nie podpisując własnych fragmentów. Zdaniem C. Leclerc, „międzyjęzykowa renga tworzy się dokładnie w opozycji do zwyczajowej hierarchii oryginału i przekładu, autora i tłumacza" ${ }^{\text {"99 }}$. Jeszcze bardziej hipotetycznie można sobie wyobrazić przekład na język trzeci opublikowany w formie oryginału francusko-angielskiego, któremu towarzyszyłoby tłumaczenie sensu stricto, ale jedynie ze stosownym komentarzem okołoprzekładowym, wprowadzającym w kontekst literacko-społeczno-polityczny Kanady i Quebecu. Byłoby to dzieło, przyznajmy, adresowane do koneserów, by nie rzec - jedynie do pasjonatów i badaczy przekładu. Może zatem niektóre dzieła, a szczególnie te tak mocno przesiąknięte przekładem, są $\mathrm{z}$ natury swej nieprzekładalne?

\section{Literatura}

Balcerzan E., 2011: Tłumaczenie jako „wojna światów”. Poznań, Wydawnictwo Naukowe UAM.

Biron M., Dumont F., Nardout-Lafarge E., 2007: Histoire de la littérature québécoise. Montréal, Boréal.

Blodgett E.D., 1982: Configuration. Essays in the Canadian Literatures. Downsview, ECW Press.

Blodgett E.D., 1991: Towards a Model of Literary. Translation in Canada. „TTR: traduction, terminologie, rédaction", vol. 4 (2), s. 189- 206.

Blodgett E.D., Brault J., 1998: Transfiguration. Saint-Hippolyte (Québec), Noroît et Toronto, BuschekBooks.

Brault J., 1975: Poèmes des quatre côtés. Québec, Éditions du Noroît.

Brault J., 1982: La Poussière du chemin. Montréal, Boréal.

Gauvin L., 2000: Langagement. Leécrivain et la langue au Québec. Montréal, Boréal.

Leclerc C., 2014: Bilinguisme officiel et traduction au Canada: les interprétations littéraires de Patrice Desbiens et de Jacques Brault / E. D. Blodgett. „Meta”, vol. 59 (3), s. 494-516.

Lemaire M., 1987: Jacques Brault essayiste. „Voix et Images”, vol. 12 (2), s. 222238.

Mammeri M., 2001: Poèmes kabyles anciens. Paris, La découverte.

Melançon C., 2000: Traduire la poésie. Présentation. „Ellipse”, no. 64, s. 9-12.

Risterucci-Roudnicky D., 2008: Introduction à l'analyse des auvres traduites. Paris, Armand Colin.

49 Ibidem, s. 501. 
Sakai N., 1997: Translation and Subjectivity. Minneapolis, University of Minnesota Press.

Simon S., 1994: Le trafic des langues. Montréal, Boréal.

Simon S., 2006: Translating Montreal: Episodes in the Life of a Divided City. Montréal \& Kingston, McGill-Queen's University Press.

Suchet M., 2017: Jacques Brault et la nontraduction, un Unland original. „TRANS-”, no. 22. Dostępne w Internecie: https://journals.openedition.org/trans/1646 [dostęp: 20.04.2018].

\section{Joanna Warmuzińska-Rogóż \\ À la charnière des deux cultures: \\ Transfiguration de Edward D. Blodgett et Jacques Brault}

RÉSUMÉ | Transfiguration est un recueil poétique dans lequel non seulement la création se transforme en traduction, mais de plus, c'est la traduction qui déclenche un acte créateur. Deux poètes canadiens, un Anglophone E.D. Blodgett et un Francophone Jacques Brault, mènent un dialogue original : chacun écrit un poème dans sa langue maternelle, et puis, chaque fragment consécutif constitue une réponse à un poème précédent, ce qui constitue une mosaïque franco-anglaise extraordinaire. Qui plus est, tout le recueil est doté d'une dimension traductologique, comme c'est Brault qui traduit les poèmes de Blodgett et vice versa. Le recueil sans précédent constitue l'un des rares exemples d'une liaison entre les deux cultures : québécoise et canadienne. De surcroît, il est une illustration intéressante du phénomène provenant de la charnière des cultures, langues et activités créatives. Le présent article décrit la spécificité de l'écriture bilingue et cherche à répondre à la question sur des possibilités de traduire un texte ainsi construit vers une troisième langue.

MOTS-CLÉS | traduction, littérature bilingue, Canada, Québec, poésie

\section{Joanna Warmuzińska-Rogóż \\ Na pograniczu twórczości i przekładu: Transfiguration Edwarda D. Blodgetta i Jacques'a Braulta}

STRESZCZENIE | Transfiguration to zbiór poetycki, w którym twórczość nie tylko płynnie przekształca się w przekład, lecz także przekład staje się punktem wyjścia dla aktu twórczego. Dwaj poeci kanadyjscy: anglojęzyczny Edward D. Blodgett oraz francuskojęzyczny Jacques Brault, prowadzą niezwykły dialog: każdy z nich pisze wiersz w swoim języku ojczystym, a kolejny utwór to odpowiedź na wiersz poprzedni, co stanowi ciekawą francusko-angielską przeplatankę. Co więcej, cały tomik zyskał także wymiar ściśle przekładowy, jako że został przetłumaczony w ten sposób, że Brault tłumaczy na język francuski utwory Blodgetta, który z kolei przekłada wiersze kolegi na język angielski. Ze wszech miar oryginalny zbiór stanowi jeden z rzadkich przejawów połączenia obu literatur: quebeckiej i kanadyjskiej oraz ciekawą ilustrację zjawiska pogranicza kultur, 
języków i działań (od)twórczych. W artykule opisano specyfikę tego rodzaju dwujęzycznej i dwukulturowej twórczości, próbując znaleźć odpowiedź na pytanie, czy możliwy jest przekład tak skonstruowanego tekstu na język trzeci.

SŁOWA KLUCZOWE | przekład, dwujęzyczna literatura, Kanada, Quebec, poezja

JOANNA WARMUZIŃSKA-ROGÓŻ | dr hab., prof. UŚ, pracownik badawczo-dydaktyczny w Instytucie Literaturoznawstwa i na kierunku filologia romańska w Uniwersytecie Śląskim w Katowicach; przekładoznawczyni, literaturoznawczyni, dydaktyk przekładu. Zajmuje się przede wszystkim współczesną literaturą quebecką. Jej zainteresowania naukowe skupiają się na postaci literackiej, pojęciu tożsamości oraz aspektach kulturowych i hybrydyczności w przekładzie. Opublikowała dwie prace monograficzne: De Langlois à Tringlot. L'effet-personnage dans les „Chroniques romanesques” de Jean Giono (2009) oraz monografię Szkice o przekładzie literackim. Literatura rodem z Quebecu w Polsce (2016), która zdobyła Nagrodę im. Pierre’a Savarda w kategorii najlepszej obcojęzycznej książki kanadystycznej. Jest współautorką Antologii współczesnej noweli quebeckiej (2011, współautor: Krzysztof Jarosz) oraz autorką kilkudziesięciu artykułów naukowych poświęconych literaturze quebeckiej i przekładowi literackiemu. 